Daniel Jose C. Mendoza, MD

Antonio H. Chua, MD

Samantha S. Castañeda, MD

Department of Otorhinolaryngology

Head and Neck Surgery

Jose R. Reyes Memorial Medical Center

Correspondence: Dr. Samantha S. Castaneda

Department of Otorhinolaryngology - Head and Neck Surgery

Jose R. Reyes Memorial Medical Center

San Lazaro Compound, Rizal Avenue

Sta. Cruz, Manila 1003

Philippines

Phone: (632) 7436921; (632) 7119491 local 320

Email: docsamcastaneda@yahoo.com

Reprints will not be available from the authors.

The authors declared that this represents original material that is not being considered for publication or has not been published or accepted for publication elsewhere, in full or in part, in print or electronic media; that the manuscript has been read and approved by all the authors, that the requirements for authorship have been met by each author, and that each author believes that the manuscript represents honest work.

Disclosures: The authors signed disclosures that there are no financial or other (including personal) relationships, intellectual passion, political or religious beliefs, and institutional affiliations that might lead to a conflict of interest.

Presented at Philippine Society of Otolaryngology - Head and Neck Surgery Free Paper Presentation, Sofitel Philippine Plaza Hotel, CCP Complex, Manila, December 4, 2012.

\title{
Unilateral Pedunculated Polyp of the Palatine Tonsil
}

\begin{abstract}
Objectives: To report a benign tonsillar lesion presenting as a pedunculated polyp and discuss its diagnosis and management.
\end{abstract}

\section{Methods:}

\author{
Design: Case Report \\ Setting: Tertiary Government Hospital \\ Patient: One
}

Results: A 14-year-old lad presented with a seven-year history of an elongated right tonsillar mass without associated bleeding, pain, dysphagia or obstructive sleep apnea. Physical examination revealed a pedunculated mass about $2 \times 1 \times 0.5 \mathrm{~cm}$ in size located in the superior pole. After unilateral tonsillectomy, histopathological examination revealed lymphangectatic lipomatous fibrotic polyp.

Conclusion: Lymphangiomatous polyp of the palatine tonsils is an unusual benign lesion of the head and neck. These are commonly present as unilateral, polypoidal mass that cannot be clinically differentiated from other benign tonsillar lesions. Tonsillectomy is the recommended surgical approach for both diagnostic and therapeutic purposes. Histopathological study must be done to confirm diagnosis.

Keywords: Palatine Tonsil, Pedunculated polyp, Hamartoma, Lymphangioma, Tonsillectomy

Tumors of the tonsils are relatively rare and benign tumors of the palatine tonsils are less common than malignancies. Squamous papillomas account for the majority of benign lesions, whereas vascular tumors are rarely reported.'Lymphangiomatous polypoid lesions of the head and neck are likewise rare and such tumors arising from the palatine tonsils are sparse. ${ }^{2}$

We present the case of an adolescent male with a lymphangiomatous polyp of the palatine tonsil.

(C) Philippine Society of Otolaryngology - Head and Neck Surgery, Inc. 


\section{CASE REPORT}

A 14-year-old healthy lad consulted at the outpatient department for an oropharyngeal foreign body sensation. On review, he had a sevenyear history of an elongated right tonsillar mass without associated bleeding, pain, dysphagia or obstructive sleep apnea. Physical examination revealed a solitary, smooth, pedunculated, elongated, pinkish, non-tender, soft mass within the right tonsillar pillar. (Figure 1)

Unilateral tonsillectomy was performed under general anesthesia. The $2 \times 1 \times 0.5 \mathrm{~cm}$ mass was attached to the superior pole of the right

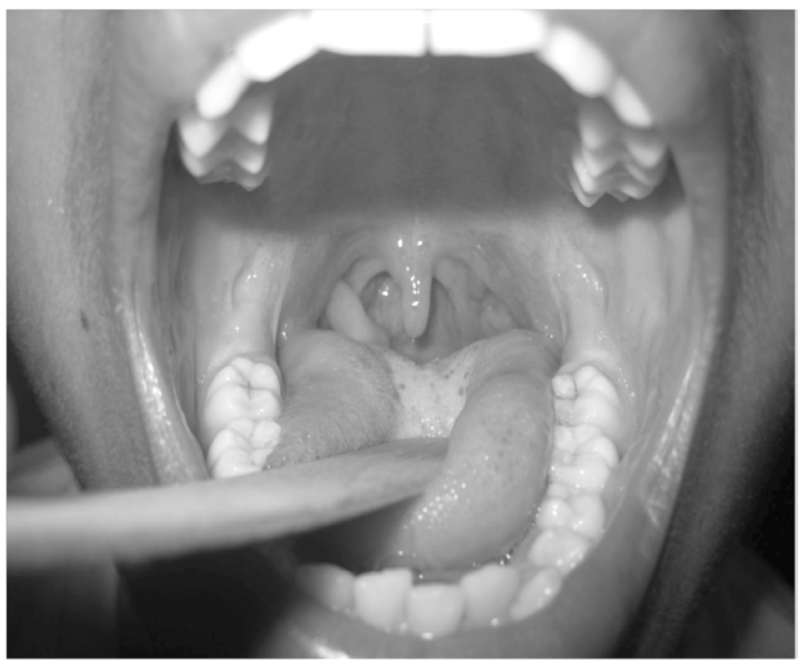

Figure 1. Oropharyngeal examination of the patient revealing a pedunculated tonsillar mass on the right.

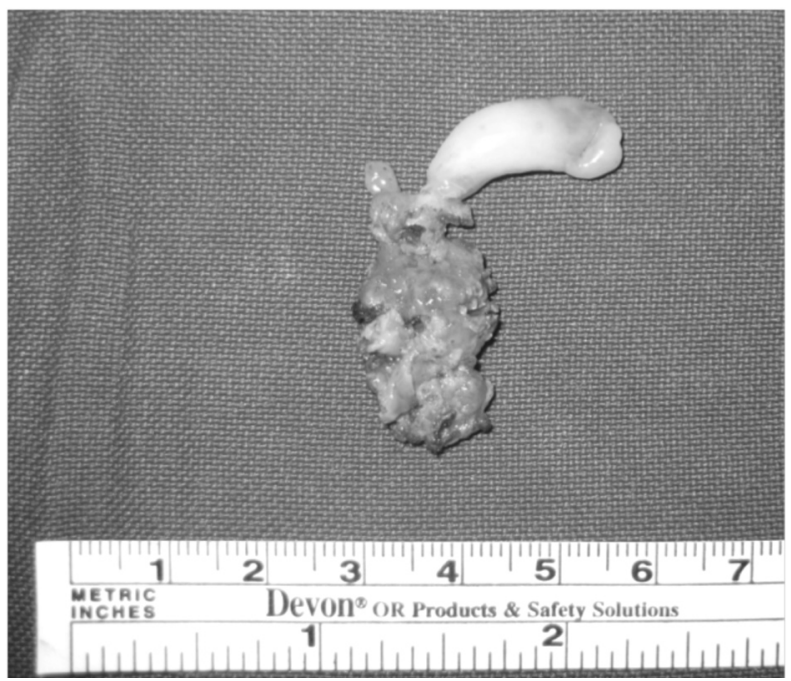

Figure 2. Right tonsil and $2 \times 1 \times 0.5 \mathrm{~cm}$ pedunculated tonsillar mass with a distinct stalk after unilateral tonsillectomy. tonsil by a distinct stalk. It was pinkish to whitish in color with soft consistency. (Figure 2) On histopathologic evaluation, the specimen showed a non-keratinizing, stratified, squamous epithelial lining and a dense lymphoid tissue at the base. (Figure 3) The central portion of the specimen contained numerous dilated lymphatic channels with thin epithelial lining and some blood vessels. (Figure 4) There was no atypia or evidence of malignancy. The final histopathological report was lymphangectatic lipomatous fibrotic polyp (a term for lymphangiomatous polyp).

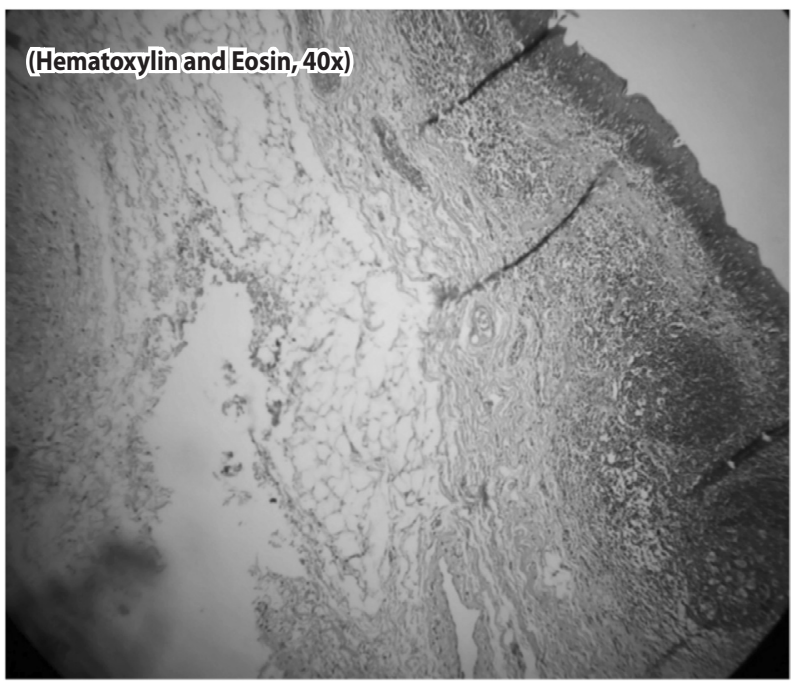

Figure 3. Histopathologic specimen showing non-keratinizing, stratified squamous epithelial lining with lymphoid tissue at the base $(\mathrm{H} \& \mathrm{E}, 40 \mathrm{x})$

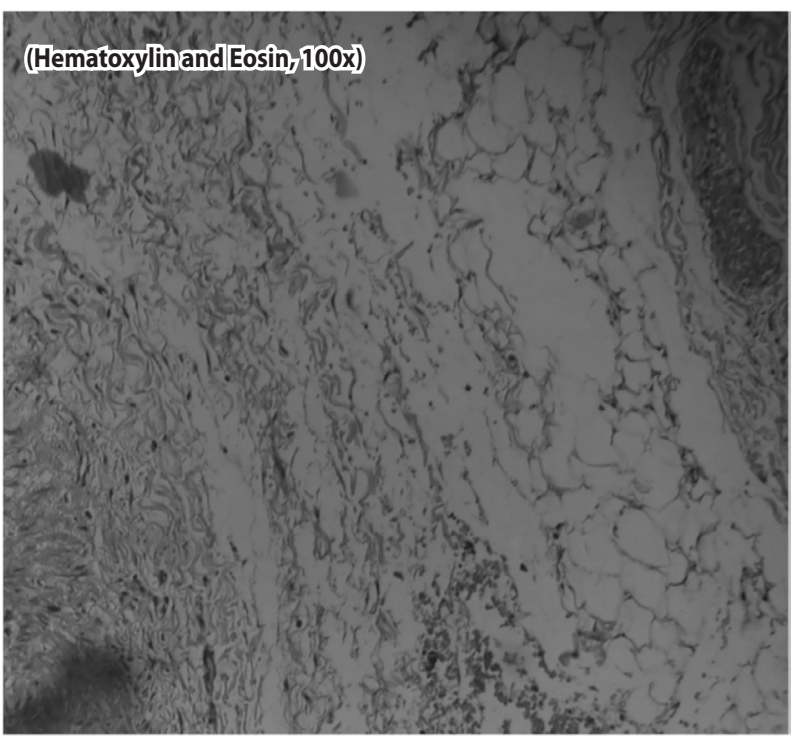

Figure 4. Histopathologic specimen showing dilated lymphatic channels in the central portion. (H\&E, 100x) 


\section{DISCUSSION}

Lymphangiomatous polyps are uncommon benign lesions. The head and neck regions are the most common sites of these lesions. The tonsil is a less common site for the development of lymphangiomatous tumors and their classification in this location is confusing. ${ }^{3}$ Different terms in the English literature have been used for classification such as lymphangectatic fibrous polyp, polypoid lymphangioma, angiofibroma, pedunculated squamous papilloma, hamartomatous tonsillar polyp, pedunculated tonsil, lipoma, lymphangectatic fibrolipomatous polyp, lymphangiomatous polyp and others. ${ }^{4}$

The true incidence of these lesions is difficult to accurately assess from the literature. This may be due to confusing histologic nomenclature used to describe benign lymphatic lesions. Lymphangiomatous polyps account for $1.9 \%$ of all tonsillar tumors seen. Another study done suggested a higher incidence for these tumors at $8 \%$ of all benign tonsillar tumors as compared to hemangiomas and fibromas representing $2 \%$ and 3\%, respectively. ${ }^{5}$ However, incidence may be higher and is only underreported and unrecognized due to its benign nature.

To our knowledge, less than 50 documented cases of tonsillar lympangiomatous polyps have been reported to date..$^{2-4,6-9}$ Of these, 26 cases were identified in a single retrospective case series from the Otolaryngologic-Head and Neck Tumor Registry of the Armed Forces Institute of Pathology. ${ }^{3}$

Most authors recommend that tonsillectomy is the curative procedure of choice. ${ }^{3-4,6}$ However, a case report recommended excision as adequate instead of tonsillectomy. ${ }^{2}$ No recurrence was reported for both tonsillectomy and excision of mass.

Adequate excision should be performed for benign tonsillar lesions. Unilateral tonsillectomy was the surgical option for this case. One of the diffential diagnoses considered was extra-pharyngeal juvenile angiofibroma which requires more aggressive resection to prevent recurrence.

\section{REFERENCES}

1. Roth M. Lymphangiomatous polyp of the palatine tonsil. Otolaryngol Head Neck Surg 1996; 115(1): 172-3.

2. Park E, Pransky SM, Malicki DM, Hong P. Unilateral lymphangiomatous polyp of the palatine tonsil in a very young child: a clinicopathologic case report. Case Rep Pedriatr. 2011; 2011: 451524. doi 10.1155/2011/451542. Epub 2012 Jan 4.

3. Kardon D, Wenig BM, Heffner DK, Thompson LD. Tonsillar lymphangiomatous polyps: a clinic pathologic series of 26 cases. Mod Pathol 2000 Oct; 13(10):1128-33.

4. Ohtsuki Y, Kurita N, Iguchi M, Kurabayashi A, Matsumoto M, Takeuchi T, et al. A pedunculated hamartomatous polyp of the palatine tonsil. Biomedical Research 2006; 17 (3): 155-8.

5. Hyams VJ. Differential diagnosis of neoplasia of the palatine tonsil. Clin Otolaryngol Allied Sci. 1978 May; 3(2): 117-26.

6. Balastouras DG, Fassolis A, Koukoutsis G, Ganelis P, Kaberos A. Primary lymphangioma of the tonsil: a case report. Case Report Med. 2011; 2011:183182. doi: 10.1155/2011/183182. Epub 2011 May 31.

7. Chen $\mathrm{HH}$, Lovell MA, Chan KH. Bilateral lymphangiomatous polyps of the palatine tonsils. Int $\mathrm{J}$ Pediatr Otorhinolaryngol. 2010 Jan; 74(1): 87-8.

8. Kasznica J, Kasznica A. Tonsillar polypoid lymphangioma in a small child. N J Med. 1991 Oct; 88(10): 729-31.

9. Al Samarrae SM, Amr SS, Hyams VJ. Polypoid lymphangioma of the tonsil: report of two cases and review of the literature. J Laryngol Otol. 1985 Aug; 99(8): 819-23. 